\title{
Níveis de Lisina Digestível em Rações, em que se Manteve ou não a Relação Aminoacídica, para Frangos de Corte de 22 a 42 Dias de Idade, Mantidos em Estresse por Calor ${ }^{1}$
}

\section{Sandra Roseli Valério², Rita Flávia Miranda de Oliveira3 ${ }^{3}$ Juarez Lopes Donzele ${ }^{3}$, Paulo Cezar Gomes $^{3}$, Lourdes Romão Apolônio ${ }^{4}$, Wilkson de Oliveira Resende ${ }^{5}$}

\begin{abstract}
RESUMO - Dois ensaios foram conduzidos para determinar a exigência de lisina digestível de frangos de corte machos dos 22 aos 42 dias de idade, recebendo rações em que se manteve ou não a relação aminoacídica e criados em estresse por calor. Utilizou-se o delineamento inteiramente casualizado em ambos os ensaios. As aves, no ensaio 1, foram distribuídas em cinco tratamentos (níveis de lisina em rações convencionais) e seis repetições, com sete aves cada. No ensaio 2, os frangos foram distribuídos em quatro tratamentos (níveis de lisina em rações mantendo a relação aminoacídica) e seis repetições, com sete aves cada. Em ambos os ensaios, os tratamentos influenciaram de forma linear crescente o ganho de peso. Embora a conversão alimentar tenha melhorado de forma linear, o modelo LRP foi o que melhor se ajustou aos dados, estimando em 0,92 e 1,022\% os níveis de lisina a partir dos quais ocorreu um platô, em rações mantendo ou não a relação aminoacídica, respectivamente. Não se verificou efeito dos tratamentos sobre o consumo de ração e sobre os pesos absoluto e relativo da carcaça das aves quando se manteve ou não a relação aminoacídica. Os níveis de lisina aumentaram linearmente o peso absoluto e o rendimento de peito dos frangos, independentemente de ter sido mantida ou não a relação aminoacídica. No ensaio 1 , os pesos absoluto e relativo da coxa e da sobrecoxa não foram influenciados pelos tratamentos, enquanto os pesos absoluto e relativo da gordura abdominal reduziram de forma linear. No ensaio 2, o peso absoluto de coxa aumentou linearmente com os níveis de lisina. No entanto, os tratamentos não influenciaram os pesos absoluto e relativo da sobrecoxa e da gordura abdominal. Concluiu-se que frangos de corte machos, no período de 22 a 42 dias de idade, mantidos em estresse por calor, exigem, no mínimo, 0,955 e 1,022\% de lisina digestível em ração convencional e em ração em que se manteve a relação aminoacídica, respectivamente.
\end{abstract}

Palavras-chave: alta temperatura, frango de corte, lisina, proteína ideal

\section{Digestible Lysine Levels in Diets Maintaining or Not the Amino Acids Relation for Broilers from 22 to 42 Days of Age Kept under Heat Stress}

\begin{abstract}
Two trials were conduced to determinate the requirement of digestible lysine of broilers from 22 to 42 days, feeding diets maintaining or not the relationship of amino acids, kept under heat stress. A completely randomized experimental design was used in both trials. In trial 1, the broilers were allotted in five treatments (lysine levels in conventional diets) and six replicates with seven broilers in each. In trial 2, the broilers were allotted in four treatments (diets with different lysine levels, maintaining the relationship of amino acids) and six replicates with seven broilers in each. In both trials, the treatments improved in a linear way the weight gain and feed:gain ratio. However, although the feed:gain ratio had been improved by linear way, the LRP model better adjusted to the data, estimating in 0.92 and $1.022 \%$ the level of lysine where occurred a plateau, when it was used the conventional diet and it was considered the relationship of amino acids. There was no effect of treatments on feed intake and on relative and absolute weight of broiler's carcass when the relationship of amino acid was maintained or not. The lysine levels increased linearly the absolute weight and yield of breast of broilers, independent of maintained or not the profile of the amino acid. In the trial 1, the absolute and relative weights of thigh and drumstick were not influenced by treatments. The absolute and relative weights of abdominal fat were reduced in a linear way by lysine levels. In the trial 2, the absolute weight of thigh increased linearly with lysine levels of diet. There was no effect of the treatments on absolute and relative weights of drumstick and abdominal fat. It was concluded that male broilers, in the period from 22 to 42 days of age, kept under heat stress require at least 0.955 and $1.022 \%$ of digestible lysine in the conventional diet and in the diet maintaining the amino acid profile, respectively.
\end{abstract}

Key Words: broilers, high temperature, ideal protein, lysine

\footnotetext{
1 Parte da Tese de Doutorado do Primeiro Autor - Projeto Financiado pela FAPEMIG

2 Professora da UFAL.

3 Professor(a) do DZO/UFV. E.mail: flavia@mail.ufv.br; donzele@mail.ufv.br

4 Estudante de Mestrado do DZO/UFV.

5 Estudante de Zootecnia - Bolsista de Iniciação Científica CNPq.
} 


\section{Introdução}

Na formulação de ração, normalmente os níveis nutricionais são expressos em porcentagem da dieta e para a obtenção do máximo desempenho das aves é preciso considerar o efeito da temperatura sobre a porcentagem de nutrientes. Sabe-se que grande parte da redução no desempenho das aves mantidas em altas temperaturas é devido à queda no consumo de alimento. Assim, para assegurar um adequado consumo de nutrientes, recomenda-se aumentar sua concentração na formulação de rações para aves mantidas em altas temperaturas.

O uso de aminoácidos essenciais na forma cristalina possibilita a redução do conteúdo de proteína da ração e o atendimento das exigências em aminoácidos essenciais, o que pode resultar em melhor balanço aminoacídico e melhor utilização dos nutrientes (Fancher \& Jensen, 1989), principalmente em condições de alta temperatura, uma vez que o incremento calórico da digestão e do metabolismo da proteína é muito elevado e, consequentemente, a ingestão de proteína em excesso aumenta a carga de calor a ser dissipado sob condições de alta temperatura (Penz, 1989). Entretanto, resultados contraditórios têm sido obtidos por Bottje \& Harrison (1985); Holsheimer \& Janssen (1991); Parr \& Summers (1991); Colnago \& Jensen (1992). Por outro lado, trabalhos realizados por Rostagno (1997) mostraram que o nível protéico das rações de frangos de corte, criados em condições de alta temperatura, pode ser reduzido pela suplementação de aminoácidos sintéticos, metionina, lisina e treonina, sem influenciar o desempenho e a qualidade da carcaça das aves. No entanto, o nível de proteína deve ser reduzido mediante o custo dos aminoácidos. Os níveis de proteína recomendados para as rações de frangos de corte, mantidos em ambientes de altas temperaturas, foram de 21 e 20,5\% para machos e fêmeas, respectivamente, para a fase inicial; e de 18,5 e 18,0\% de PB para machos e fêmeas, respectivamente, para o período final.

Na moderna avicultura industrial, a otimização da produção de carne magra de alta qualidade requer um adequado e preciso suprimento de nutrientes em razão do potencial genético e das condições ambientais. Segundo Smith (1993), a temperatura ambiente influencia o rendimento de peito e a composição da carcaça de frangos. Além disso, a exposição de animais a temperaturas altas provoca diversas mudanças adaptativas fisiológicas, dentre elas a modificação no tamanho dos órgãos, alterando, consequentemente, a exigência nutricional dos animais, uma vez que o gasto de energia pelos tecidos metabolicamente ativos como fígado, intestino e rins é muito maior do que aquele associado à carcaça. Mudanças no tamanho e na taxa metabólica dos tecidos internos como coração, fígado, rins e intestino, em razão de sua alta taxa de gasto de energia, relativa a seu tamanho, podem ter substancial impacto sobre o requerimento de mantença do animal (Ferre \& Koong, 1986).

Desta forma, realizou-se este estudo para avaliar níveis de lisina digestível em rações em que se manteve ou não a relação aminoacídica, para frangos de corte machos de 22 a 42 dias de idade, criados sob condições de alta temperatura $\left(29^{\circ} \mathrm{C}\right)$.

\section{Material e Métodos}

Os ensaios foram conduzidos no Laboratório de Bioclimatologia Animal do Departamento de Zootecnia do Centro de Ciências Agrárias da Universidade Federal de Viçosa, em Viçosa, MG.

Ensaio 1 - Níveis de lisina digestível em rações convencionais para frangos de corte de 22 a 42 dias de idade, criados em ambiente de alta temperatura

Foram utilizados 210 frangos de corte machos, Avian Farms, com peso inicial médio de $681 \pm 5,01 \mathrm{~g}$, mantidos em salas climatizadas com temperatura e umidade relativa constantes de $29,1 \pm 0,13^{\circ} \mathrm{C}$ e de 61 $\pm 2,5 \%$, respectivamente (Tabela 1 ).

Tabela 1 - Condições ambientais observadas nas câmaras climáticas durante o período experimental, para frangos de corte de 22 a 42 dias de idade 1

Table 1 - Environmental conditions observed in the climatic chambers during the experimental period for broilers from 22 to 42 days of age

Temperatura do ar $(\mathrm{C})$

$29,1 \pm 0,12$

Air temperature

Umidade relativa (\%)

$61 \pm 2,5$

Relative humidity

Temperatura de globo negro (C)

Black globe temperature

Índice de temperatura de globo

e umidade (ITGU)

Black Globe Humidity Index - BGHI

${ }^{1}$ Valores médios (Average values). 
Durante o período inicial (1 a 21 dias de idade), as aves foram criadas em galpão convencional, recebendo ração com $3000 \mathrm{kcal}$ de $\mathrm{EM} / \mathrm{kg}$ e $21 \%$ de $\mathrm{PB}$, para satisfazer suas exigências nutricionais, segundo Rostagno et al. (1996) e manejadas conforme Lana (2000).

No $22^{\circ}$ dia de idade, os frangos foram pesados e transferidos para as câmaras climáticas, quando teve início o período experimental. As aves foram alojadas em baterias, com compartimentos de $0,85 \times 0,85 \mathrm{~m}$, providos de comedouro e bebedouro tipo calha. As condições ambientais das salas foram monitoradas diariamente, duas vezes ao dia, por meio de termômetros de bulbo seco e bulbo úmido, de globo negro e de máxima e mínima, mantidos no centro das salas. $\mathrm{O}$ programa de luz adotado foi o contínuo (24 horas de luz artificial) durante todo período experimental, utilizando-se duas lâmpadas fluorescentes de 75 watts por sala. As aves foram distribuídas em delineamento inteiramente casualizado, com cinco tratamentos, seis repetições e sete aves por cada repetição.

Os tratamentos consistiram de uma ração basal (Tabela 2) formulada à base de milho, farelo de soja e glúten de milho, para atender as exigências das aves, segundo recomendações de Rostagno et al. (1996), exceto em lisina. A ração basal foi suplementada com L-lisina $99 \%(0,00 ; 0,06 ; 0,12$; 0,18 e $0,24 \%$ de lisina) em substituição ao caulim, resultando em rações experimentais contendo $0,88 \mathrm{e}$ $0,775 \% ; 0,94$ e $0,835 \%$; 1,00 e $0,895 \% ; 1,06$ e $0,955 \%$; 1,12 e $1,015 \%$ de lisina total e digestível, respectivamente. Os valores de aminoácidos totais dos ingredientes da ração experimental foram obtidos por meio de análises laboratoriais, os quais, em seguida, foram corrigidos para aminoácidos digestíveis, utilizando-se os coeficientes de digestibilidade das tabelas Rhodimet-Rhône-Poulenc (1993) (Tabela 3). O fornecimento de ração e água foi ad libitum, sendo a água trocada três vezes ao dia.

As aves foram pesadas no início e no final do período experimental para determinação do ganho de peso. Da mesma forma, o consumo de ração foi calculado considerando-se a ração fornecida e as sobras das rações nos comedouros. Posteriormente, calculou-se a conversão alimentar pela razão entre o consumo de ração e o ganho de peso das aves.

As análises estatísticas das variáveis estudadas foram realizadas por intermédio do programa SAEG (Sistema para Análises Estatísticas), desenvolvido na Universidade Federal de Viçosa - UFV (1999). As estimativas de exigências de lisina digestível para frangos de corte, no período de 1 a 21 dias de idade, mantidos em condições de estresse por calor, foram estabelecidas com base nos resultados de desempenho, por meio de modelos de regressão linear, quadrática e, ou descontínuo "Linear Response Plateau" (LRP), conforme o melhor ajuste obtido para cada variável.

Tabela 2 - Composição percentual da ração basal Table 2 - Percentual composition of basal diet

\begin{tabular}{|c|c|}
\hline $\begin{array}{l}\text { Ingredientes } \\
\text { Ingredients }\end{array}$ & $(\%)$ \\
\hline$\overline{\text { Milho (Corn) }}$ & 66,280 \\
\hline Farelo de soja (Soybean meal) & 21,204 \\
\hline Glúten de milho (Corn gluten) & 6,702 \\
\hline Fosfato bicálcico (Dicalcium phosphate) & 1,536 \\
\hline Calcário (Limestone) & 1,233 \\
\hline Óleo vegetal (Vegetable oil) & 1,240 \\
\hline Sal comum (Salt) & 0,415 \\
\hline Mistura vitamínica $(\text { Vitamin mix })^{1}$ & 0,050 \\
\hline Mistura mineral (Mineral mix $)^{2}$ & 0,100 \\
\hline Anticoccidiano $(\text { Anticoccidian })^{3}$ & 0,050 \\
\hline $\mathrm{BHT}^{4}$ & 0,010 \\
\hline Cloreto de colina (Choline chloride $)^{5}$ & 0,125 \\
\hline Stafac $^{6}$ & 0,055 \\
\hline Caulim & 0,844 \\
\hline L-Lisina (L-lysine) $(99 \%)$ & 0,000 \\
\hline DL-Metionina (DL-methionine) $(99 \%)$ & 0,154 \\
\hline L-Triptofano (L-triptophan) $(99 \%)$ & 0,002 \\
\hline \multicolumn{2}{|l|}{$\begin{array}{l}\text { Composição calculada } \\
\text { Calculated composition }\end{array}$} \\
\hline Proteína bruta (Crude protein) $(\%)$ & 19,6 \\
\hline Energia metabolizável (kcal/kg) & 3.100 \\
\hline \multicolumn{2}{|l|}{ Metabolizable energy } \\
\hline Lisina total (Total lysine) $(\%)$ & 0,880 \\
\hline Lisina digestível (Digestible lysine) (\%) & 0,775 \\
\hline Metionina+cistina digestível $(\%)$ & 0,709 \\
\hline \multicolumn{2}{|l|}{ Digestible met + cys } \\
\hline Triptofano digestível (Digestible tryptophan) (\%) & 0,168 \\
\hline Cálcio (Calcium) $(\%)$ & 0,920 \\
\hline Fósforo disponível (Available phosphorus) (\%) & 0,390 \\
\hline Sódio (Sodium) (\%) & 0,200 \\
\hline \multicolumn{2}{|c|}{ 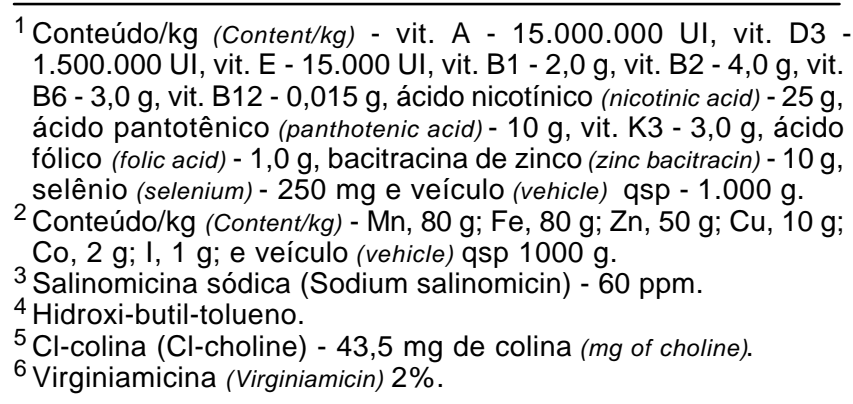 } \\
\hline
\end{tabular}


Ensaio 2 - Níveis de lisina digestível em rações, em que se manteve a relação aminoacídica, para frangos de corte de 22 a 42 dias de idade, criados em ambiente de alta temperatura

Foram utilizados 168 frangos de corte machos, da linhagem Avian Farms, com peso inicial médio de 647 $\pm 3,2$ g. O ensaio foi conduzido com aves no período de 22 a 42 dias de idade, em câmaras climáticas, com temperatura e umidade relativa controladas (Tabela 1).

Durante o período inicial (1 a 21 dias de idade), as aves foram criadas em galpão convencional, recebendo ração com $3000 \mathrm{kcal}$ de EM/kg e $21 \%$ de PB, para satisfazer suas exigências nutricionais, segundo Rostagno et al. (1996) e manejadas conforme Lana (2000).

No $22^{\mathrm{O}}$ dia de idade, os frangos foram pesados e transferidos para as câmaras climáticas, quando teve início o período experimental. As aves foram alojadas em baterias, com compartimentos de $0,85 \times 0,85 \mathrm{~m}$, providos de comedouro e bebedouro tipo calha. As condições ambientais das salas foram monitoradas diariamente, duas vezes ao dia, por meio de termômetros de bulbo seco e bulbo úmido, de globo negro e de máxima e mínima, que foram mantidos no centro das salas. O programa de luz adotado foi o contínuo (24 horas de luz artificial) durante todo período experimental, utilizando-se duas lâmpadas fluorescentes que forneciam 75 watts por sala. As aves foram distribuídas em delineamento experimental inteiramente casualizado, com quatro tratamentos, seis repetições e sete aves por repetição.

Os frangos receberam ração experimental (Tabela 4) à base de milho, farelo de soja e glúten de milho, seguindo as recomendações de Rostagno et al. (1996). As rações foram suplementadas com L-lisina 99\%, resultando em rações contendo 1,00 e $0,895 \%$; 1,06 e $0,955 \% ; 1,12$ e $1,015 \% ; 1,18$ e $1,075 \%$ de lisina total e digestível, respectivamente. As concentrações dos aminoácidos DL-metionina, L-treonina, Ltriptofano, L-valina, L-isoleucina e L-arginina, em relação à lisina, foram mantidas em quantidades no mínimo suficientes para se obter o padrão de proteína ideal, conforme preconizado por Baker (1994), citado por Parsons \& Baker (1994), para aminoácidos digestíveis, onde a lisina equivale a $100 \%$, a metionina + cistina a $75 \%$, a treonina a $70 \%$, o triptofano a $17 \%$, a valina a $77 \%$, a isoleucina a $67 \%$ e a arginina a $105 \%$. Os valores dos aminoácidos totais dos ingredientes das rações experimentais foram obtidos por meio de análises laboratoriais, sendo posteriormente corrigidos para aminoácidos digestíveis, utilizando-se os coeficientes de digestibilidade das tabelas Rhodimet- Rhône-Poulenc (1993). O fornecimento de ração e água foi ad libitum, sendo a água trocada três vezes ao dia.

Tabela 3 - Composição em aminoácidos totais e digestíveis dos ingredientes das rações

Table 3 - Total and digestible amino acids composition of diets ingredients

\begin{tabular}{|c|c|c|c|c|c|c|}
\hline \multirow[t]{2}{*}{$(\%)$} & \multicolumn{2}{|c|}{$\begin{array}{l}\text { Milho } \\
\text { Corn }\end{array}$} & \multicolumn{2}{|c|}{$\begin{array}{l}\text { Farelo de soja } \\
\text { Soybean meal }\end{array}$} & \multicolumn{2}{|c|}{$\begin{array}{l}\text { Glúten de milho } \\
\text { Corn gluten }\end{array}$} \\
\hline & $\begin{array}{l}\mathrm{AAT}^{1} \\
\mathrm{TAA}^{1}\end{array}$ & $\begin{array}{l}\mathrm{AAD}^{2} \\
\mathrm{DAA}^{2}\end{array}$ & $\begin{array}{l}\mathrm{AAT}^{1} \\
\mathrm{TAA}^{1}\end{array}$ & $\begin{array}{l}\mathrm{AAD}^{2} \\
\mathrm{DAA}^{2}\end{array}$ & $\begin{array}{l}\text { AAT }^{1} \\
\text { TAA }^{1}\end{array}$ & $\begin{array}{l}\mathrm{AAD}^{2} \\
\mathrm{DAA}^{2}\end{array}$ \\
\hline Lisina (Lysine) & 0,2730 & 0,2239 & 2,9634 & 2,6374 & 1,0558 & 1,0030 \\
\hline Metionina (Methionine) & 0,1588 & 0,1477 & 0,4300 & 0,3913 & 1,4552 & 1,3970 \\
\hline Met+cis $($ Meth + Cys $)$ & 0,3213 & 0,2809 & 1,0404 & 0,9045 & 2,2027 & 2,0922 \\
\hline Treonina (Threonine) & 0,2558 & 0,2174 & 1,8994 & 1,6525 & 2,0694 & 2,0073 \\
\hline Isoleucina (Isoleucine) & 0,2166 & 0,1971 & 2,0166 & 1,8149 & 2,7621 & 2,6792 \\
\hline Arginina (Arginine) & 0,2919 & 0,2715 & 3,4906 & 3,2812 & 2,2243 & 2,2021 \\
\hline Valina (Valine) & 0,3749 & 0,3337 & 2,1104 & 1,8571 & 3,0156 & 2,9553 \\
\hline Glicina+Ser $($ Glycine + ser $)$ & 0,6117 & 0,5312 & 4,4794 & 3,9525 & 4,6493 & 4,3833 \\
\hline Triptofano (Thryptophan) & 0,0628 & 0,0565 & 0,4354 & 0,3657 & 0,5370 & 0,5209 \\
\hline Leucina (Leucine) & 0,8913 & 0,8467 & 3,6415 & 3,2773 & 11,0267 & 10,8062 \\
\hline Fenilalanina (Phenilalanine) & 0,3235 & 0,3041 & 2,2336 & 2,0326 & 4,1781 & 4,1363 \\
\hline Histidina (Hystidine) & 0,3028 & 0,2786 & 1,3539 & 1,2320 & 1,3964 & 1,3685 \\
\hline Tirosina (Tyrosine) & 0,0994 & 0,0924 & 1,3953 & 1,2837 & 3,0971 & 3,0352 \\
\hline Prolina (Proline) & 0,7504 & - & 2,6615 & - & 6,9537 & - \\
\hline Proteína bruta (Crude protein) & \multicolumn{2}{|c|}{8,35} & \multicolumn{2}{|c|}{46,81} & & 61,77 \\
\hline
\end{tabular}

${ }^{1}$ Aminoácido total, determinado pelo Laboratório da Guabi - Mogiana Alimentos - Campinas, SP (Total amino acid determined by Guabi Laboratory - Mogiana Feeds - Campinas, SP).

${ }^{2}$ Aminoácido digestível, calculado pelo coeficiente de digestibilidade das tabelas Rhodimet... (1993) (Digestible amino acid calculated using digestibility coefficients of Rhodimet... tables (1993). 
Tabela 4 - Composição percentual das rações experimentais

Table 4 - Percentual composition of the experimental diets

\begin{tabular}{|c|c|c|c|c|}
\hline \multirow[t]{2}{*}{$\begin{array}{l}\text { Ingredientes } \\
\text { Ingredients }\end{array}$} & \multicolumn{4}{|c|}{$\begin{array}{c}\text { Níveis de lisina digestível (\%) } \\
\text { Digestible lysine levels }\end{array}$} \\
\hline & 0,895 & 0,955 & 1,015 & 1,075 \\
\hline Milho (Corn) & 66,280 & 66,280 & 66,280 & 66,280 \\
\hline Farelo de soja (Soybean oil) & 21,204 & 21,204 & 21,204 & 21,204 \\
\hline Glúten de milho (Corn gluten) & 6,702 & 6,702 & 6,702 & 6,702 \\
\hline Fosfato bicálcico (Dicalcium phosphate) & 1,536 & 1,536 & 1,536 & 1,536 \\
\hline Calcário (Limestone) & 1,233 & 1,233 & 1,233 & 1,233 \\
\hline Óleo vegetal (Vegetable oil) & 1,240 & 1,240 & 1,240 & 1,240 \\
\hline Sal comum (Salt) & 0,415 & 0,415 & 0,415 & 0,415 \\
\hline Mistura vitamínica (Vitamin mix) ${ }^{1}$ & 0,050 & 0,050 & 0,050 & 0,050 \\
\hline Mistura mineral (Mineral mix $)^{2}$ & 0,100 & 0,100 & 0,100 & 0,100 \\
\hline Anticoccidiano (Anticoccidian $)^{3}$ & 0,050 & 0,050 & 0,050 & 0,050 \\
\hline $\mathrm{BHT}^{4}$ & 0,010 & 0,010 & 0,010 & 0,010 \\
\hline Cloreto de colina $(\text { Choline chloride })^{5}$ & 0,125 & 0,125 & 0,125 & 0,125 \\
\hline Stafac $^{6}$ & 0,055 & 0,055 & 0,055 & 0,055 \\
\hline Caulim & 0,691 & 0,518 & 0,300 & 0,017 \\
\hline L-Lisina (L-Lysine) & 0,153 & 0,230 & 0,306 & 0,383 \\
\hline DL-Metionina (DL-Methionine) & 0,154 & 0,200 & 0,246 & 0,292 \\
\hline L- Treonina (L-Threonine) & 0,000 & 0,040 & 0,083 & 0,126 \\
\hline L- Triptofano (L-Tryptophan) & 0,002 & 0,0124 & 0,0228 & 0,0332 \\
\hline L- Valina (L-Valine) & 0,000 & 0,000 & 0,000 & 0,014 \\
\hline L- Isoleucina (L-Isoleucine) & 0,000 & 0,000 & 0,000 & 0,029 \\
\hline L- Arginina (L-Arginine) & 0,000 & 0,000 & 0,042 & 0,106 \\
\hline \multicolumn{5}{|l|}{$\begin{array}{l}\text { Composição calculada } \\
\text { Calculated composition }\end{array}$} \\
\hline Proteína bruta (Crude protein) $(\%)$ & 19,6 & 19,6 & 19,6 & 19,6 \\
\hline Energia metabolizável (kcal/kg) & 3.100 & 3.100 & 3.100 & 3.100 \\
\hline \multicolumn{5}{|l|}{ Metabolizable energy } \\
\hline Lisina digestível (\%) & 0,895 & 0,955 & 1,015 & 1,075 \\
\hline Digestible lysine & & & & \\
\hline Met + cis digestível $(\%)$ & 0,672 & 0,718 & 0,764 & 0,810 \\
\hline \multicolumn{5}{|l|}{ Digestible met + cys } \\
\hline Treonina digestível (\%) & 0,629 & 0,669 & 0,712 & 0,755 \\
\hline \multicolumn{5}{|l|}{ Digestible threonine } \\
\hline Triptofano digestível (\%) & 0,152 & 0,162 & 0,173 & 0,183 \\
\hline \multicolumn{5}{|l|}{ Digestible tryptophan } \\
\hline Valina digestível (\%) & 0,814 & 0,814 & 0,814 & 0,828 \\
\hline \multicolumn{5}{|l|}{ Digestible valine } \\
\hline Isoleucina digestível (\%) & 0,692 & 0,692 & 0,692 & 0,720 \\
\hline \multicolumn{5}{|l|}{ Digestible isoleucine } \\
\hline Arginina digestível (\%) & 1,024 & 1,024 & 1,066 & 1,129 \\
\hline \multicolumn{5}{|l|}{ Digestible arginine } \\
\hline $\begin{array}{l}{ }^{1} \text { Conteúdo/kg (Content/kg) - vit. A - } 15.000 .00 \\
\text { vit. B12 - 0,015 g, ácido nicotínico (nicotinic } \\
\text { - } 1,0 \mathrm{~g} \text {, bacitracina de zinco (zinc bacitracin) } \\
2 \text { Conteúdo/kg (Content } / \mathrm{kg} \text { ) - Mn, } 80 \mathrm{~g} ; \mathrm{Fe}, 8 \\
{ }^{3} \text { Salinomicina sódica (Sodium salinomicin) - } 60 \\
{ }^{4} \text { Hidroxi-butil-tolueno. } \\
{ }^{5} \text { Cl-colina - } 43,5 \mathrm{mg} \text { de colina (Cl-choline } 43.5 \\
6 \text { Virginiamicina } 2 \% \text { (Virginiamicin). }\end{array}$ & $\begin{array}{l}.500 .000 \text { Ul } \\
\text { do pantotêr } \\
\text { (selenium) - } \\
\text { d, } 10 \mathrm{~g} \text {; Co, }\end{array}$ & $\begin{array}{l}5.000 \text { UI, vit. } \\
\text { thenic acid) - } \\
\text { veículo (vehi } \\
\text {; e veículo (v }\end{array}$ & $\begin{array}{l}\text { g, vit. B2 - } \\
\text { K3 - 3,0 g, á } \\
-1.000 \mathrm{~g} . \\
\text { sp - } 1000 \mathrm{~g} \text {. }\end{array}$ & $\begin{array}{l}\text { vit. B6 - 3,0 g } \\
\text { fólico (folic acio }\end{array}$ \\
\hline
\end{tabular}

Os procedimentos de monitoramento do ambiente, fornecimento de ração, determinação das medidas de desempenho e de rendimento de carcaça, análise e modelo estatístico foram idênticos aos do ensaio 1 .

\section{Resultados e Discussão}

Os resultados de desempenho e de consumo de lisina digestível dos frangos de corte que foram 
alimentados com rações contendo diferentes níveis de lisina digestível, em que se manteve ou não a relação aminoacídica, no período de 22 a 42 dias de idade, e mantidos sob condições de estresse por calor são apresentados na Tabela 5 .

Foi verificado aumento linear no peso final dos frangos aos 42 dias de idade, recebendo rações com diferentes níveis de lisina, mantendo-se $(\mathrm{P}<0,01)$ ou não $(\mathrm{P}<0,05)$ a relação aminoacídica, segundo as respectivas equações: $\hat{Y}=1321,33+582,301 X$ $\left(\mathrm{r}^{2}=0,80\right)$ e $\hat{\mathrm{Y}}=1589,09+313,664 \mathrm{X}\left(\mathrm{r}^{2}=0,48\right)$. Estes resultados corroboraram aqueles obtidos por Han \& Baker (1994) e Conhalato et al. (1998), que constataram variação no peso final dos frangos em razão dos níveis de lisina da ração, quando estes foram criados em condições de conforto térmico. Por outro lado, Conhalato et al. (1999) não verificaram aumento no peso final dos frangos aos 42 dias de idade, quando mantidos em conforto térmico, à medida que a concentração de lisina na ração foi aumentada.

Os níveis de lisina das diferentes rações influenciaram o ganho de peso dos frangos mantidos sob estresse por calor, que aumentou linearmente segundo a equação: $\hat{Y}=679,530+577,057 \mathrm{X}$ $\left(\mathrm{r}^{2}=0,81\right)$, quando se considerou a relação aminoacídica $(\mathrm{P}<0,01)$; e $\hat{\mathrm{Y}}=923,466+296,442 \mathrm{X}$ $\left(\mathrm{r}^{2}=0,46\right)$, quando se utilizou a ração convencional $(\mathrm{P}<0,05)$, sem considerar o conceito de proteína ideal. Estes resultados estão coerentes com aqueles de Holsheimer \& Ruesink (1993), Scheuermann et al. (1994), Han \& Baker (1994), Conhalato et al. (1997), Conhalato (1998), Leclercq (1998), Conhalato et al. (1999), Costa et al. (1999) e Barboza et al. (2000), que também verificaram aumento no ganho de peso dos frangos mantidos em conforto térmico, à medida que se elevou os níveis de lisina da ração. Em contrapartida, discordam daqueles obtidos por Mendes et al. (1997) e Costa et al. (2000), que não observaram efeito dos níveis de lisina e das diferentes relações arginina:lisina sobre o ganho de peso dos frangos mantidos em alta temperatura.

Apesar de o ganho de peso ter aumentado de forma linear, verificou-se que, a partir do nível de $1,015 \%$ de lisina digestível, este não variou em valores absolutos quando se utilizou a ração em que se corrigiu o balanço aminoacídico. Constatou-se também que quando não se considerou a relação entre a lisina e os demais aminoácidos essenciais, o ganho de peso entre os dois maiores níveis de lisina $(0,955 \mathrm{e}$ $1,015 \%$ ) reduziu em $4,6 \%$, provavelmente em razão da limitação de algum aminoácido essencial.

O nível de 1,015\% de lisina digestível, correspon-

Tabela 5 - Efeito dos níveis de lisina digestível na ração, em que se manteve ou não a relação aminoacídica, sobre o desempenho de frangos de corte, no período de 22 a 42 dias de idade, mantidos em condições de estresse de calor

Table 5 - Effect of dietary levels of digestible lysine maintaining or not the relation of the amino acids on performance of broilers from 22 to 42 days of age kept under heat stress environment

\begin{tabular}{|c|c|c|c|c|c|c|c|c|c|c|c|}
\hline \multirow[t]{3}{*}{$\begin{array}{l}\text { Variáveis } \\
\text { Variables }\end{array}$} & \multicolumn{8}{|c|}{$\begin{array}{l}\text { Níveis de lisina digestível (\%) } \\
\text { Digestible lysine levels }\end{array}$} & & & \\
\hline & \multicolumn{6}{|c|}{$\begin{array}{c}\text { Ração convencional } \\
\text { Conventional diet }\end{array}$} & \multicolumn{5}{|c|}{$\begin{array}{l}\text { Ração mantendo relação aminoacídica } \\
\text { Diet maintaining the amino acid relation }\end{array}$} \\
\hline & 0,775 & 0,835 & 0,895 & 0,955 & 1,015 & $\mathrm{CV}$ & 0,895 & 0,955 & 1,015 & 1,075 & $\mathrm{CV}$ \\
\hline $\begin{array}{l}\text { Peso final }(\mathrm{g}) \\
\text { Final weight }\end{array}$ & $1841 \mathrm{~L} 2$ & 1818 & 1879 & 1931 & 1879 & 3,22 & 1838 L1 & 1867 & 1945 & 1929 & 3,50 \\
\hline $\begin{array}{l}\text { Ganho de peso }(\mathrm{g}) \\
\text { Weight gain }\end{array}$ & 1160 L2 & 1142 & 1197 & 1250 & 1195 & 5,15 & 1192 L1 & 1220 & 1296 & 1283 & 5,28 \\
\hline $\begin{array}{l}\text { Consumo de ração }(\mathrm{g}) \\
\text { Feed intake }\end{array}$ & 2543 & 2491 & 2526 & 2610 & 2521 & 4,16 & 2382 & 2396 & 2426 & 2395 & 5,20 \\
\hline $\begin{array}{l}\text { Consumo de lisina digestível (g) } \\
\text { Digestible lysine intake }\end{array}$ & 19,7 L1 & 20,8 & 22,6 & 24,9 & 25,6 & 4,21 & 21,3 L1 & 22,9 & 24,6 & 25,7 & 5,24 \\
\hline $\begin{array}{l}\text { Conversão alimentar } \\
\text { Feed:gain ratio }\end{array}$ & 2,19 L2 & 2,18 & 2,11 & 2,09 & 2,11 & 3,74 & 2,00 L1 & 1,96 & 1,87 & 1,86 & 3,22 \\
\hline $\begin{array}{l}\text { Eficiência de utilização de } \\
\text { lisina para ganho de peso* } \\
\text { Efficiency of lysine utilization for } w\end{array}$ & $\begin{array}{l}58,9 \\
\text { gain }^{*}\end{array}$ & 54,9 & 52,9 & 50,2 & 46,7 & 56,0 & 53,3 & 52,7 & 49,9 & & \\
\hline
\end{tabular}

L1, L2 Efeito linear $(P<0,01)$ e $(P<0,05)$, respectivamente (Linear effect $[P<.01]$ and $[P<.05]$, respectively).

* Calculado como g de ganho de peso/g de lisina consumida (Calculated as $g$ of weight gain/g of lysine intake). 
dente a $1,12 \%$ de lisina total, obtido para máximo ganho de peso quando se considerou a relação aminoacídica, foi maior que 0,85 e $0,815 \%$ de lisina digestível estabelecidos por Han \& Baker (1994) e Emmert \& Baker (1997), respectivamente. Entretanto, foi próximo aos níveis de 1,02 e $1,045 \%$ de lisina digestível, recomendados por Conhalato et al. (1998 e 1999) e Rostagno et al. (2000), para frangos de corte de 22 a 42 dias de idade, criados em condições de conforto térmico.

Não houve efeito $(\mathrm{P}>0,05)$ dos diferentes níveis de lisina das rações sobre o consumo de ração dos frangos mantidos sob estresse de calor, independentemente de ter sido mantida ou não a relação entre a lisina e os demais aminoácidos essenciais considerados críticos para as aves. Resultados semelhantes foram obtidos por Mendes et al. (1997) que não observaram variação significativa dos níveis de lisina e das diferentes relações arginina:lisina sobre o consumo de alimentos das aves mantidas em temperaturas elevadas $\left(25,5\right.$ a $\left.33,3^{\circ} \mathrm{C}\right)$. Em contrapartida, Han \& Baker (1994), Conhalato et al. (1997), Knowles \& Southern (1998), Conhalato et al. (1999) e Costa et al. (1999) constataram variação sobre o consumo de ração das aves em razão dos diferentes níveis de lisina da ração, quando criadas em condições de termoneutralidade.

A variação não-significativa do consumo de ração das aves que receberam a ração em que se corrigiu o balanço aminoacídico foi justificado pelo fato de as rações terem sido isoenergéticas e da relação entre a lisina e os aminoácidos considerados mais críticos para as aves, metionina+cistina, treonina, triptofano, valina, isoleucina e arginina, ter sido mantida nos diferentes níveis de lisina avaliados.

Embora não tenha ocorrido efeito dos níveis de lisina sobre o consumo de alimentos quando se utilizou as rações convencionais, observou-se variação no consumo de ração de 4,4 a 9,4\% entre as aves que receberam a ração com $0,955 \%$ de lisina digestível em relação às que receberam os demais níveis estudados. Desta forma, pode-se verificar que a ração com $0,955 \%$ de lisina digestível, correspondendo a $1,06 \%$ de lisina total, proporcionou o maior consumo (1250 g). Portanto, o resultado de consumo de ração, neste trabalho, permitiu inferir que, possivelmente, o desequilíbrio de aminoácidos ocasionado pelas alterações nos níveis de lisina não foi suficiente para influenciar negativamente esse parâmetro.

Verificou-se efeito linear crescente $(\mathrm{P}<0,01)$ dos níveis de lisina sobre o consumo de lisina digestível dos frangos de corte aos 42 dias de idade e mantidos em condições de estresse de calor, de acordo com a equação: $\hat{Y}=-1,01495+25,0344 X\left(r^{2}=0,99\right)$, quando se considerou a relação aminoacídica; e $\hat{\mathrm{Y}}=-0,965357+26,4744 \mathrm{X}\left(\mathrm{r}^{2}=0,98\right)$, quando se utilizou as rações convencionais. Estes resultados estão de acordo com aqueles obtidos por Conhalato et al. (1999), em condições de termoneutralidade. Por outro lado, Conhalato et al. (1998) não verificaram influência dos diferentes níveis de lisina mantendo a relação aminoacídica sobre o consumo de lisina digestível para frangos de corte de 22 a 42 dias de idade e mantidos sob condições de conforto térmico.

Com relação à conversão alimentar, constatou-se redução linear em razão dos níveis de lisina da ração, mantendo-se $(\mathrm{P}<0,01)$ ou não $(\mathrm{P}<0,05)$ a relação entre a lisina e os demais aminoácidos essenciais considerados críticos para as aves. No entanto, o modelo "Linear Response Plateau" - LRP foi o que melhor se ajustou aos dados, estimando em $0,92 \%$ de lisina digestível quando se utilizou a ração convencional e $1,022 \%$ quando se considerou a relação aminoacídica (Figuras 1 e 2). Estes resultados corroboraram aqueles obtidos por Scheuermann et al. (1994), Han \& Baker (1994), Conhalato et al. (1997, 1998, 1999), Leclercq (1998), Costa et al. (1999) e Barboza et al. (2000), que verificaram redução na conversão alimentar dos frangos criados em condições de termoneutralidade em razão dos diferentes níveis de lisina das rações. Por outro lado, Mendes et al. (1997) não constataram melhora na conversão alimentar das aves em razão do aumento dos níveis de lisina na ração, quando mantidas em alta temperatura.

Embora tenha ocorrido similaridade de resposta, constatou-se que entre os três níveis de lisina comuns aos dois tipos de rações utilizadas $(0,895,0,955$ e 1,015\%) a conversão alimentar dos frangos que receberam a ração em que se considerou a relação aminoacídica foi de 5,2 a $11,4 \%$ melhor. Considerando essa diferença na resposta de conversão alimentar, a eficiência de utilização de lisina para ganho de peso entre os três níveis de lisina comuns foi de 5,9 a $12,8 \%$ maior para os frangos que receberam a ração com a relação entre a lisina e os demais aminoácidos essenciais corrigida.

Os valores dos pesos absolutos e relativos da carcaça, dos cortes nobres e da gordura abdominal, obtidos para os frangos de corte aos 42 dias de idade e mantidos em condições de estresse de calor, são apresentados nas Tabelas 6 e 7. 


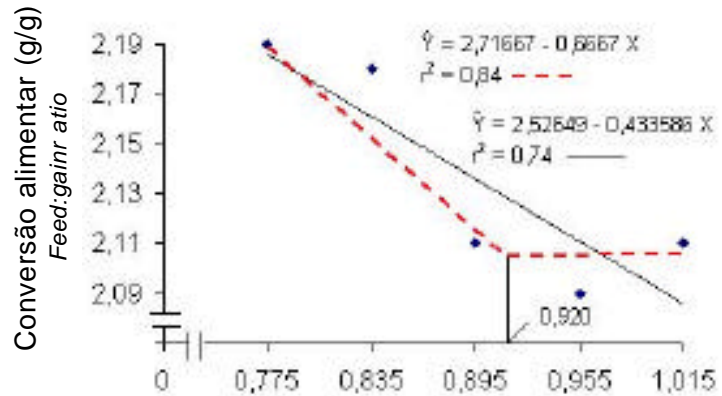

Níveis de lisina digestível (\%)

Levels of digestible lysine

Figura 1 - Efeito dos níveis de lisina da ração convencional sobre a conversão alimentar dos frangos aos 42 dias, mantidos em ambiente de alta temperatura.

Figure 1 - Effect of lysine levels in conventional diet on feeed:gain ratio of broilers at 42 days of age kept under high environmental temperature.

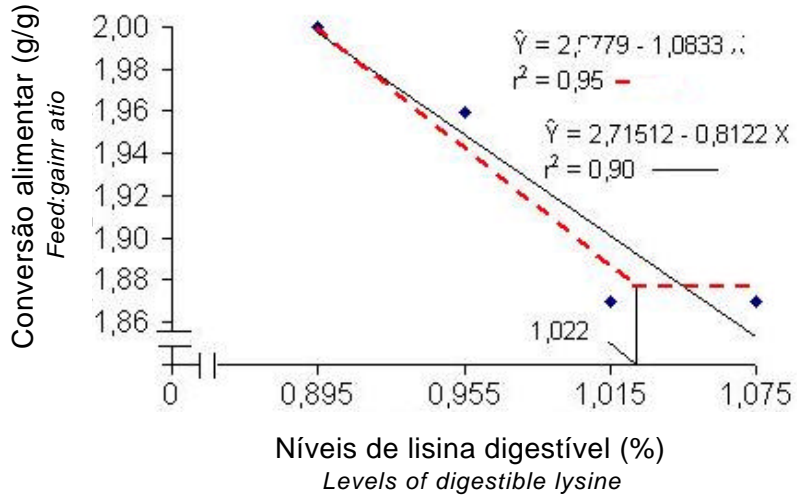

Figura 2 - Efeito dos níveis de lisina da ração, em que se manteve a relação aminoacídica, sobre a conversão alimentar dos frangos aos 42 dias, mantidos em condições de estresse de calor.

Figure 2 - Effect of dietary lysine levels maintaining the amino acid relation on feed:gain ratio of broilers at 42 days of age kept under high environmental temperature.

Tabela 6 - Valores dos pesos absolutos e relativos da carcaça, dos cortes nobres e da gordura abdominal para frangos aos 42 dias de idade, mantidos em condições de estresse de calor, recebendo rações com diferentes níveis de lisina, em que se manteve ou não a relação aminoacídica

Table 6 - Values of absolute and relative weights of carcass of parts and of abdominal fat for broilers at 42 days of age kept under heat stress environment feeding diets with different lysine levels maintaining or not the amino acid relation

\begin{tabular}{|c|c|c|c|c|c|c|c|c|c|c|c|}
\hline \multirow[t]{3}{*}{$\begin{array}{l}\text { Variáveis } \\
\text { Variables }\end{array}$} & \multicolumn{9}{|c|}{$\begin{array}{c}\text { Níveis de lisina digestível (\%) } \\
\text { Digestible lysine levels }\end{array}$} & & \\
\hline & \multicolumn{6}{|c|}{$\begin{array}{l}\text { Ração convencional } \\
\text { Conventional diet }\end{array}$} & \multicolumn{5}{|c|}{$\begin{array}{l}\text { Ração mantendo relação aminoacídica } \\
\text { Diet maintaining the amino acid relation }\end{array}$} \\
\hline & 0,775 & 0,835 & 0,895 & 0,955 & 1,015 & $\mathrm{CV}$ & 0,895 & 0,955 & 1,015 & 1,075 & $\mathrm{CV}$ \\
\hline \multicolumn{12}{|l|}{$\begin{array}{l}\text { Peso absoluto (g) } \\
\text { Absolute weight }\end{array}$} \\
\hline $\begin{array}{l}\text { Carcaça } \\
\text { Carcass }\end{array}$ & 1504 & 1476 & 1501 & 1537 & 1498 & 4,50 & 1513 & 1483 & 1522 & 1501 & 7,40 \\
\hline $\begin{array}{l}\text { Peito } \\
\text { Breast }\end{array}$ & $389^{\mathrm{L} 1}$ & 375 & 412 & 420 & 417 & 8,40 & $383^{\mathrm{L} 1}$ & 404 & 419 & 414 & 8,03 \\
\hline $\begin{array}{l}\text { Coxa } \\
\text { Thigh }\end{array}$ & 194 & 192 & 199 & 197 & 192 & 6,55 & $189^{\mathrm{L} 1}$ & 198 & 197 & 203 & 5,95 \\
\hline $\begin{array}{l}\text { Sobrecoxa } \\
\text { Drumstick }\end{array}$ & 196 & 196 & 209 & 200 & 196 & 6,84 & 187 & 197 & 198 & 191 & 10,08 \\
\hline $\begin{array}{l}\text { Gordura abdominal } \\
\text { Abdominal fat }\end{array}$ & $29^{\text {L1 }}$ & 21 & 23 & 25 & 16 & 19,33 & 24 & 21 & 23 & 24 & 14,36 \\
\hline \multicolumn{12}{|l|}{$\begin{array}{l}\text { Peso relativo (\%) } \\
\text { Relative weight }\end{array}$} \\
\hline $\begin{array}{l}\text { Carcaça } \\
\text { Carcass }\end{array}$ & 80,32 & 79,87 & 79,64 & 80,17 & 79,89 & 1,26 & 79,89 & 79,78 & 79,92 & 80,02 & 1,40 \\
\hline $\begin{array}{l}\text { Peito } \\
\text { Breast }\end{array}$ & $25,9^{\mathrm{L} 2}$ & 26,0 & 26,4 & 27,0 & 27,8 & 4,46 & $24,4^{\mathrm{L} 2}$ & 27,3 & 27,8 & 27,7 & 10,44 \\
\hline $\begin{array}{l}\text { Coxa } \\
\text { Thigh }\end{array}$ & 13,0 & 13,0 & 12,8 & 12,8 & 12,9 & 3,86 & 12,5 & 13,4 & 13,0 & 13,6 & 9,03 \\
\hline $\begin{array}{l}\text { Sobrecoxa } \\
\text { Drumstick }\end{array}$ & 13,3 & 13,2 & 13,7 & 13,0 & 13,4 & 4,74 & 12,4 & 13,3 & 13,1 & 12,8 & 12,41 \\
\hline $\begin{array}{l}\text { Gordura abdominal } \\
\text { Abdominal fat }\end{array}$ & $1,91^{\mathrm{L} 1}$ & 1,45 & 1,52 & 1,63 & 1,11 & 19,27 & 1,55 & 1,44 & 1,51 & 1,59 & 14,71 \\
\hline
\end{tabular}

${ }^{L 1}, \mathrm{~L} 2$ Efeito linear $(P<0,01)$ e $(P<0,05)$, respectivamente (Linear effect $[P<.01]$ and $[P<.05]$ respectively). 
Tabela 7 - Regressão de diferentes variáveis sobre os níveis de lisina digestível das rações

Table 7 - Regression equations of different variables on dietary digestible lysine levels

\begin{tabular}{|c|c|c|}
\hline $\begin{array}{l}\text { Item } \\
\text { Item }\end{array}$ & $\begin{array}{l}\text { Equação de regressão } \\
\text { Regression equations }\end{array}$ & \\
\hline $\begin{array}{l}\text { Peso absoluto de peito* } \\
\text { Absolute weight of breast }\end{array}$ & $\hat{\mathrm{Y}}=230,230+190,991 \mathrm{X}$ & $\mathrm{r}^{2}=0,66$ \\
\hline $\begin{array}{l}\text { Peso absoluto de peito** } \\
\text { Absolute weight of breast } * *\end{array}$ & $\hat{\mathrm{Y}}=228,405+179,306 \mathrm{X}$ & $r^{2}=0,75$ \\
\hline $\begin{array}{l}\text { Peso relativo de peito* } \\
\text { Relative weight of breast }\end{array}$ & $\hat{\mathrm{Y}}=18,6892+8,8234 \mathrm{X}$ & $\mathrm{r}^{2}=0,93$ \\
\hline $\begin{array}{l}\text { Peso relativo de peito** } \\
\text { Absolute weight of breast** }\end{array}$ & $\hat{\mathrm{Y}}=14,8974+12,3325 \mathrm{X}$ & $r^{2}=0,73$ \\
\hline $\begin{array}{l}\text { Peso absoluto de coxa** } \\
\text { Absolute weight of thigh** }\end{array}$ & $\hat{Y}=129,168+68,6111 X$ & $\mathrm{r}^{2}=0,80$ \\
\hline $\begin{array}{l}\text { Peso relativo de coxa** } \\
\text { Absolute weight of thigh** }\end{array}$ & $\hat{\mathrm{Y}}=8,41732+4,79237 \mathrm{X}$ & $r^{2}=0,61$ \\
\hline $\begin{array}{l}\text { Peso absoluto de gordura abdominal* } \\
\text { Absolute weight of abdominal fat* }\end{array}$ & $Y=54,0706-34,6847 X$ & $r^{2}=0,47$ \\
\hline $\begin{array}{l}\text { Peso relativo de gordura abdominal* } \\
\text { Relative weight of abdominal fat }{ }^{*}\end{array}$ & $Y=3,74688-2,47742 X$ & $\mathrm{r}^{2}=0,57$ \\
\hline
\end{tabular}

Os pesos absoluto e relativo da carcaça dos frangos aos 42 dias de idade não foram influenciados $(\mathrm{P}>0,05)$ pelos diferentes níveis de lisina avaliados, independentemente de ter sido mantida ou não a relação aminoacídica.Estes resultados sãocoerentescomaqueles obtidos por Mendes et al. (1997) quando avaliaram diferentes níveis de lisina e relações arginina:lisina para

Verificou-se variação linear dos diferentes níveis de lisina digestível sobre o peso absoluto $(\mathrm{P}<0,01) \mathrm{e}$ o relativo $(\mathrm{P}<0,05)$ de peito dos frangos aos 42 dias de idade, independentemente de ter sido corrigido ou não o balanço aminoacídico (Tabelas 6 e 7). Estes resultados corroboraram aqueles obtidos por Moran Jr. \& Bilgili (1990), Hickling et al.(1990), Holsheimer \& Veerkamp (1992), Han \& Baker (1994), Leclercq (1998), Costa et al. (1999) e Barboza et al. (2000), para frangos criados sob condições de conforto térmico. Por outro lado, Mendes et al. (1997) não constataram aumento no rendimento de peito de frangos mantidos sob condições de alta temperatura em razão dos diferentes níveis de lisina da ração. Conhalato et al. (1998) também não observaram variação significativa sobre o rendimento de peito à medida que se elevou a concentração de lisina da ração em que se manteve a relação com os demais aminoácidos essenciais.

Os níveis de lisina da ração convencional, sem considerar o conceito de proteína ideal, não influenciaram
$(\mathrm{P}>0,05)$ o peso absoluto e o relativo de coxa dos frangos aos 42 dias de idade e mantidos em condições de estresse por calor. Entretanto, o peso absoluto de coxa das aves que receberam a ração em se manteve a relação aminoacídica variou $(\mathrm{P}<0,01)$ de forma linear (Tabelas 6 e 7).

Não houve efeito $(\mathrm{P}>0,05)$ dos tratamentos sobre o peso absoluto e o relativo de sobrecoxa das aves aos 42 dias, mantidas sob condições de alta temperatura, independentementedeter-se utilizadoaraçãoconvencional ou a ração em que se corrigiu o balanço aminoacídico.

Constatou-se redução linear $(\mathrm{P}<0,01)$ no peso absoluto e no peso relativo da gordura abdominal dos frangos que receberam as rações convencionais (Tabelas 6 e 7). Resultados semelhantes foram obtidos por Mendes etal. (1997) eCosta et al.(2000) que constataram redução no teor de gordura abdominal das aves mantidas em altas temperaturas. Estes resultados corroboraram aqueles constatados por Moran Jr. \& Bilgili (1990), Han \& Baker (1994), Leclercq (1998), Costa et al. (1999). Por outro lado, Scheuermann et al. (1994) não constataram reduções no conteúdo de gordura abdominal dos frangos à medida que se elevou o nível de lisina da ração, em condições de conforto térmico.

Não foi constatado efeito $(\mathrm{P}>0,05)$ dos níveis de lisina sobre os pesos absoluto e relativo da gordura abdominal dos frangos aos 42 dias, mantidos em ambiente 
de alta temperatura, quando estes receberam rações em que se manteve a relação aminoacídica. Estes resultados estão de acordo com aqueles obtidos por Scheuermann et al. (1994). Por outro lado, Moran Jr. \& Bilgili (1990), Han \& Baker (1994) e Costa et al. (1999) constataram reduções lineares no conteúdo de gordura abdominal dos frangos à medida que se elevou o nível de lisina da ração, em condições de termoneutralidade.

Como, entre os níveis de 1,015 e 1,075\% de lisina digestível, os valores de ganho de peso, consumo de ração, pesos absolutos de carcaça, de peito e de sobrecoxa tenderam a reduzir nas aves que receberam as rações em que se corrigiu o balanço aminoacídico, pode-se inferir que, em condições de alta temperatura, a limitação na capacidade de dissipação de calor das aves é fator determinante à sua resposta à nutrição protéica. De acordo com Hruby et al. (1995), a inabilidade de frangos de corte para dissipar o calor corporal, em ambientes de alta temperatura, compromete o seu desempenho quando se aumenta a ingestão diária de proteína e aminoácidos.

\section{Conclusões}

Em condições de estresse de calor o nível de lisina digestível da ração convencional, de no mínimo $0,955 \%$, correspondente a $1,06 \%$ de lisina total e ao consumo estimado de $24,3 \mathrm{~g}$ de lisina digestível, propiciou os melhores resultados de desempenho de frangos de corte machos, da linhagem Avian Farms, de 22 a 42 dias de idade.

A exigência de lisina digestível, mantendo-se a relação entre a lisina e os demais aminoácidos, metionina+cistina, triptofano, treonina, valina, isoleucina e arginina, para frangos de corte machos, de 22 a 42 dias de idade, mantidos em ambiente de alta temperatura, foi estimada em, no mínimo, 1,022\%, correspondendo a $1,12 \%$ de lisina total e ao consumo estimado de lisina digestível de 24,6 g.

\section{Literatura Citada}

BAKER, D.H., HAN, Y. Ideal amino acid profile for chickens during the first three weeks posthatching. Poultry Science, v.73, p.1441-1447, 1994.

BARBOZA, W.A.; ROSTAGNO, H.S.; ALBINO, L.F.T. et al. Níveis de lisina para frangos de corte de 22 a 40 e 42 a 48 dias de idade. Revista Brasileira Zootecnia, v.29, p.10911097, 2000.

BOTTJE, W.G.; HARRISON, P.C. Effect of carbonated water on growth performance of cockerels subjected to constant and cyclic heat stress temperatures. Poultry Science, v.64, p.12851292, 1985.

COLNAGO, G.L.; JENSEN, L.S. Putrescine effects on performance of male broiler chicks fed low-protein diets supplemented with essential amino acids. Poultry Science, v.71, p.211-214, 1992.

CONHALATO, G.S. Exigência de lisina digestível para frangos de corte machos. Viçosa, MG: Universidade Federal de Viçosa, 1998. 68p. Dissertação (Mestrado em Zootecnia) - Universidade Federal de Viçosa, 1998.

CONHALATO, G.S.; DONZELE, J.L.; ALBINO, L.F.T. et al. Níveis de lisina digestível para frangos de corte machos na fase de 22 a 42 dias de idade. Revista Brasileira Zootecnia, v.28, p.98-104, 1999.

CONHALATO, G.S.; DONZELE, J.L.; OLIVEIRA, R.F.M. et al. Níveis de lisina digestível mantendo a relação dos aminoácidos para frangos de corte machos na fase de 22 a 42 dias de idade. In: REUNIÃO ANUAL DA SOCIEDADE BRASILEIRA DE ZOOTECNIA, 35., 1998, Botucatu. Anais... Botucatu: Sociedade Brasileira de Zootecnia, 1998. p.282.

CONHALATO, G.S.; DONZELE, J.L.; FONTES, D. Níveis de lisina digestível para frangos de corte machos na fase de 22-42 dias de idade. In: REUNIÃO ANUAL DA SOCIEDADE BRASILEIRA DE ZOOTECNIA., 34., 199, Juiz de Fora, MG. Anais... Juiz de Fora: Sociedade Brasileira de Zootecnia, 1997. p.54.

COSTA, F.G.P.; ROSTAGNO, H.S.; TOLEDO, R.S. Efeito da relação arginina:lisina sobre o desempenho e qualidade de carcaça de frangos de corte criados em condições de alta temperatura. In: REUNIÃO ANUAL DA SOCIEDADE BRASILEIRA DE ZOOTECNIA., 37., 2000, Viçosa, MG. Anais... Viçosa, MG: Sociedade Brasileira de Zootecnia, 2000. p.276.

COSTA, F.G.P.; ROSTAGNO, H.S.; ALBINO, L.F.T. et al. Níveis dietéticos de lisina para frangos de corte, no período de 22 a 40 dias de idade. In: CONFERÊNCIA APINCO DE CIÊNCIA E TECNOLOGIA AVÍCOLAS, 1999, Campinas. Anais... Campinas: 1999. p.18.

EMMERT, M.W.; BAKER, D.H. Use of the ideal protein concept for precision formulation of amino acid levels in broilers diets. Journal of Applied Poultry Research, v.6, p.462-470, 1997.

FANCHER, B.; JENSEN, L.S. Male broiler performance during the starting and growing periods as affected by dietary proteins, essencial amino acids, and potassium levels. Poultry Science, v.68, p.1385-1395, 1989.

FERRE, C.L.; KOONG, K.J. Influence of plane nutrition on body composition, organ size and energy utilization of spraguedawley rats. Journal of Nutrition, v.116, p.2525-2535, 1986.

HAN, Y.; BAKER, D.H. Digestible lysine requirements of male and female broiler chicks during the period three to six weeks posthatching. Poultry Science, v.73, p.1739-1745, 1994.

HICKLING, D.; GUENTER, W.; JACKSON, M.E. The effect of methionine and lysine on broilers chicken performance and breast meat yield. Canadian Journal of Animal Science, v.70, p.673-678, 1990.

HOLSHEIMER, J.P.; JANSSEN, W.M.M.A. Limiting amino acid $\mathrm{s}$ in low protein maize soybean meal diets fed to broiler chicks from 3 to 7 weeks of age. British Poultry Science, v.32, p.151158, 1991.

HOLSHEIMER, J.P.; VEERKAMP, C.H. Effect of dietary energy and lysine content on performance and yields of two strains of male broiler chicks. Poultry Science, v.71, p.872-879, 1992.

HRUBY, M.; HAMRE, M.L.; COON, G.N. Predicting amino acid requirements for broilers at $21.1^{\circ} \mathrm{C}$ and $32.2^{\circ} \mathrm{C}$. Journal of Applied Research, v.4, p.4395-4301, 1995. 
KNOWLES, T.A.; SOUTHERN, L.L. The lysine requirement and ratio of total sulfur amino acids to lysine for chicks fed adequate or inadequate lysine. Poultry Science, v.77, p.564-569, 1998.

LANA, G.R.Q. Avicultura. 1.ed. Campinas, SP: Livraria e Editora Rural Ltda, 2000. 268p.

LECLERCQ, B. Specific effects of lysine on broiler production: Comparison with threonine and valine.Poultry Science, v.77, p.118-123, 1998.

MENDES, A.A.; WATKINS, J.A.; ENGLAND, E.A. et al. Influence of dietary lysine levels and arginine:lysine ratios on performance of broilers exposed to heat or cold stress during the period of three to six weeks of age.Poultry Science, v.76, p.472-481, 1997.

MORAN JR., E.T.; BILGILI, S.F. Processing losses, carcass quality and meat yield of broiler chickens as influenced by dietary lysine. Poultry Science, v.69, p.702-709, 1990.

OLOMU, J.M.; OFFIONG, S.A. The effects of different protein and energy levels and time of change form starter to finisher ration on the performance of broiler chicken in the tropics. Poultry Science, v.59, p.828-835, 1980.

PARR, J.F.; SUMMERS, J.D. The effects of minimizing amino acid excess in broiler diets. Poultry Science, v.70, p.1540-1549, 1991.

PARSONS, C.M.; BAKER, D.H. The concept and use of ideal proteins in feeding of nonruminants. In: REUNIÃO ANUAL DA SOCIEDADE BRASILEIRA DE ZOOTECNIA., 31., 1994, Maringá. Anais... Maringá: Sociedade Brasileira de Zootecnia, 1994. p.128.

PENZ, A.M. Estresse pelo calor: Efeitos em frangos de corte e matrizes. Manipulação do equilíbrio ácido-base. In: CONFERÊNCIA APINCO DE CIÊNCIA E TECNOLOGIA AVÍCOLA, 1989, São Paulo.Anais... São Paulo: 1989.p.139-146.

RHODIMET feed formulation guide. 6.ed. France: Rhône-Poulenc Animal Nutrition, 1993. 39p.
ROSTAGNO, H.S.; ALBINO, L.F.T.; DONZELE, J.L. et al. Tabelas brasileiras para aves e suínos (Composição de alimentos e exigências nutricionais). Viçosa, MG: Universidade Federal de Viçosa, 2000. 141p.

ROSTAGNO, H.S.; BARBARINO JR., P.; BARBOZA, W.A. Exigências nutricionais das aves determinadas no Brasil. In: SIMPÓSIO INTERNACIONAL SOBRE EXIGÊNCIAS NUTRICIONAIS DE AVES E SUÍNOS, 1996, Viçosa, MG. Anais... Viçosa, MG: Universidade Federal de Viçosa, 1996. p.361.

ROSTAGNO, H.S. Rações com diferentes níveis de proteína para frangos de corte. In:ENCONTRO DENUTRIÇÃO ANIMAL, 3., 1997, São Paulo, Degussa, 1-10.

SCHEUERMANN, G.N.; MAIER, J.C.; BELLAVER, C. et al. Exigência de lisina para frangos de corte de 21 a 42 dias de idade. In: REUNIÃO ANUAL DA SOCIEDADE BRASILEIRA DE ZOOTECNIA, 31., 1994, Maringá. Anais... Maringá:Sociedade Brasileira de Zootecnia, 1994. p.128.

SMITH, M.O. Parts yield of broilers reared under cycling high temperatures. Poultry Science, v.72, p.146-150, 1993.

UNIVERSIDADE FEDERAL DE VIÇOSA - UFV. Manual de Utilização do Programa SAEG (Sistema para Análises Estatísticas 8.0). Viçosa, MG: Universidade Federal de Viçosa, 1999. 141p.
Recebido em: 05/04/02

Aceito em: 14/10/02 